\title{
Salmonella infection acquired from reptilian pets
}

\author{
D Sanyal, T Douglas, R Roberts
}

\begin{abstract}
Two children presented with signs and symptoms of gastroenteritis. Salmonella chameleon was isolated from the stool of one child and also from an iguana kept in the home as a pet. Salmonella arizonae was isolated from the stool of the other child and also from four snakes sharing the same household. Exotic reptiles are unsuitable pets to share the home environment with infants.

(Arch Dis Child 1997;77:345-346)
\end{abstract}

Keywords: salmonella infection; reptiles; pets

Salmonella infection is commonly described in children and adults. In sporadic cases the cause is usually undetermined, but is occasionally linked to a food source-for example, chicken or eggs. We present two cases in which an unusual salmonella serotype was isolated from a symptomatic child. This, in turn, was associated with the domestic presence of a reptilian pet from which the same salmonella serotype was isolated.

\section{Case reports}

CASE 1

A previously well 11 day old boy was admitted after a 24 hour history of passing stools streaked with blood and mucus, irritability, and refusal of feeds. On examination he appeared febrile and septic, with abdominal tenderness. An abdominal ultrasound and radiograph were normal. He was treated with intravenous antibiotics (ampicillin, metronidazole, and gentamicin) and admitted for observation. Stool samples were sent to the microbiology laboratory for culture and grew an organism resembling a salmonella species in its colonial morphology and biochemistry, but which did not agglutinate with the usual salmonella antisera. A provisional diagnosis of salmonella gastroenteritis was made. Blood, urine, and cerebrospinal fluid cultures taken on admission showed no growth. The infant made a rapid and uneventful recovery while receiving the antibiotic regimen and was eventually discharged home eight days after admission.

The stool isolate was eventually conclusively identified as a Salmonella chameleon by the Laboratory of Enteric Pathogens, Colindale. This is a salmonella of the group IV subgenus and is particularly associated with reptiles such as lizards and geckos. Questioning of the family revealed that a green iguana (Iguana iguana) was kept as a family pet. Stool specimens were obtained from the iguana and these also grew $S$ chameleon.
No other family member reported any gastrointestinal symptoms during this time and stool samples provided from the parents were also negative. The iguana had no discernible signs of gastrointestinal upset, but was returned to the pet shop. The child continued to have loose green stools and remained positive for $S$ chameleon six months later.

CASE 2

The second case was a full term boy who was diagnosed at 8 weeks of age as having Netherton's syndrome. This is a rare icthyosiform syndrome of unknown cause leading to erythroderma, skin sloughing, malabsorption, and variable immune deficiencies. He was treated with regular applications of white soft paraffin and liquid paraffin. His skin was maintained in a stable condition and he was allowed home on weekend leave. A feature of Netherton's syndrome is failure to thrive and, as this child's nutritional status was unsatisfactory, regular nasogastric feeding was started at home.

On one occasion, at 5 months of age, shortly after returning from a weekend at home, he developed profuse diarrhoea with a small amount of vomiting. There was no sign of systemic illness. The infant was rehydrated and treated with ciprofloxacin by mouth. Stool samples were sent to the laboratory. He rapidly settled on antibiotic treatment and was asymptomatic five days after admission.

The stool specimens grew an organism with a colonial morphology consistent with a salmonella species. Serology and biochemistry also confirmed it as such, but it was evidently an unusual serotype. It was identified as Salmonella arizonae by the Laboratory of Enteric Pathogens. This is a salmonella of the group III subgenus and is commonly associated with snakes. Inquiries showed that the father was a breeder of snakes, 15 of which lived in the home. Stool cultures from the snakes were sent to the laboratory and $S$ arizonae was grown from four species (chequered garter snake, Russian rat snake, milk snake, and northern pine snake). Three of the four $S$ arizonae isolates had an identical antigenic structure to that obtained from the patient. No other family member had symptoms of gastroenteritis or grew $S$ arizonae in their stools. The father had been involved in the nasogastric feeding of the infant, but maintained that he had always been scrupulous in his hygiene. The four snakes positive for salmonella were destroyed. The infant subsequently recovered after a course of ciprofloxacin.

\section{Discussion}

Salmonella species are widely distributed in animals and most infections in humans are 
acquired from eating contaminated foodstuffs. Salmonella serotypes of subgroups III and IV are found in reptiles such as turtles, terrapins, lizards, and snakes. Infections of humans associated with handling these animals have been regularly described. ${ }^{1}$ Terrapins and turtles were first implicated as vectors of salmonellosis, particularly of Salmonella java. These reptiles were popular as domestic pets in the 1970s and 1980 s and were noted then to cause infections, particularly in children. ${ }^{2}$ After a series of outbreaks public health measures were introduced for the care and management of terrapins. $^{3}$

Iguanas are now popular as 'exotic' pets, especially in the USA. Their association with salmonella infection in young children has been noted by paediatricians in that country. A study in Colorado implicated green iguanas in five cases of salmonella infection in children. The same rare serotype was isolated from patients' stools and iguanas in each circumstance. ${ }^{4}$ After three cases of salmonellosis associated with iguanas in New York state, investigators conducted a case-control study and found a strong association between reptile ownership and infection with rare serotypes of salmonella. ${ }^{5}$ Most of the cases but no controls shared the household with an iguana. Most infected patients were less than 6 months of age. A recent national study in the USA showed the association between Salmonella marinum infection and iguana exposure; $81 \%$ of cases were infants less than 1 year of age. ${ }^{6}$ The authors provide a number of recommendations for preventing the transmission of salmonella from reptiles to humans.

Infections due to $S$ arizonae have been described in the UK. ${ }^{7}$ A significant number of cases were in households where snakes were kept as pets and most symptomatic infections were in children less than 5 years of age. In one example a snake breeder transmitted the infection from a snake to his two children. Infection with $S$ arizonae has also been described in association with other reptiles such as terrapins. Infection with $S$ arizonae is a more common phenomenon in the southwestern USA. In this situation it is usually seen in adults who have consumed infected rattlesnake meat as a 'folk medicine'. ${ }^{8}$ A case report from Phoenix, Arizona describes a 6 year old Hispanic boy who developed severe gastroenteritis due to $S$ arizonae after ingesting sundried rattlesnake meat. ${ }^{9}$

Reptiles are symptomless carriers of salmonella species, probably having become infected through contaminated food, water, or soil. The fact that the animals show no symptom may indicate that the bacteria exist as commensal flora in the animal's gut. A reptile may carry more than one salmonella serotype and excretion of bacteria may be intermittent. ${ }^{1}$ Previous studies have shown widespread contamination of the home environment in cases of salmonellosis associated with reptiles. ${ }^{56}$ Young infants are at particular risk of acquiring salmonella in these circumstances. Often these infections are invasive, leading to complications such as salmonella meningitis and septicaemia. ${ }^{10}$ Reptiles are increasingly popular as unusual pets. They are now recognised as an important public health hazard in the USA. Paediatricians in the UK should take note and discourage the ownership of reptiles in households with children less than 5 years of age.

We are grateful to Drs C Ewing and E Wraith for permission to report their patients and to staff of the Laboratory of Enteric Pathogens, Central Public Health Laboratory, PHLS Colindale for identifying the isolates.

1 Anonymous. Reptilian salmonellosis [Editorial]. Lancet

1981;ii:130-1.
2 Orton WT, Henderson WG. The infected terrapin. CommuOrton WT, Henderson WG. The
nity Medicine 1972;127:89-91.

3 Ball D. Varieties, importation and care of terrapins. Community Medicine 1972;127:91-2.

4 Dalton C, Hoffman R, Pape J. Iguana-associated salmonellosis in children. Pediatr Infect Dis $\mathcal{F}$ 1995;14:319-20.

5 Ackman DM, Drabkin P, Birkhead G, Cieslak P. Reptileassociated salmonellosis in New York State. Pediatr Infect Dis f 1995;14:955-9.

6 Mermin J, Hoar D, Angulo FJ. Iguanas and Salmonella marina infection in children: a reflection of the increasing incidence of reptile-associated salmonellosis in the United States. Pediatrics 1997;99:399-402.

7 Hall MLM, Rowe B. Salmonella arizonae in the United Kingdom from 1966 to 1990 . Epidemiol Infect 1992;108:5965.

8 Waterman SH, Jurrez G, Carr SJ, Kilman L. Salmonella arizonae infections in Latinos associated with a rattlesnake olk medicine. Am F Public Health 1990;80:286-9.

9 Kelly J, Hopkin R, Rimsza R. Rattlesnake meat ingestion and Salmonella arizonae infection in children: case report and review of the literature. Pediatr Infect Dis $\mathcal{f}$ 1995;14: 320-2.

10 Makin G, Abu-Harb M, Finn A, Partridge S. Salmonella durban in an infant. Lancet 1996;348:200. 